\title{
Sectoral co-movements of employment growth at regional level
}

\section{Marco Capasso, Koen Frenken \& Tania Treibich}

To cite this article: Marco Capasso, Koen Frenken \& Tania Treibich (2017) Sectoral comovements of employment growth at regional level, Economic Systems Research, 29:1, 82-104, DOI: $10.1080 / 09535314.2017 .1281232$

To link to this article: http://dx.doi.org/10.1080/09535314.2017.1281232

+ View supplementary material

Published online: 01 Feb 2017.

Submit your article to this journal

山 Article views: 32

Q View related articles $\sqsubset$

View Crossmark data $־$ 


\title{
Sectoral co-movements of employment growth at regional level
}

\author{
Marco Capasso ${ }^{a, b, c}$, Koen Frenken ${ }^{d, e}$ and Tania Treibich ${ }^{a, f}$ \\ a School of Business and Economics, Maastricht University, Maastricht, The Netherlands; $\mathrm{b}$ Institute of

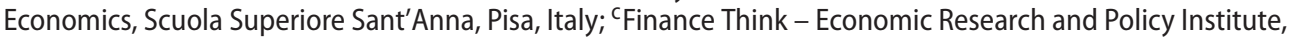 \\ Skopje, Republic of Macedonia; ${ }^{d}$ Innovation Studies, Copernicus Institute of Sustainable Development, \\ Utrecht University, Utrecht, The Netherlands; ${ }^{\mathrm{e}} \mathrm{CIRCLE}$, Lund University, Lund, Sweden; ${ }^{\mathrm{f} O F C E}$, Paris, France
}

\begin{abstract}
This paper presents a comprehensive study of sectoral co-movements of employment growth in the entire Dutch economy. We construct different macro typologies according to manufacturing versus services, innovativeness, labour skills and position in the value chain, thus expanding the list of potential logics of sectoral interrelations. Using a vector autoregression model, we assess whether and how growth in a macro-sector, and in a given region, can predict growth in the same or other macro-sectors, in the same or in other regions. Our findings bring to light the inter-regional nature of intersectoral linkages, as well as the existence of complementarities between sectors. Supporting the growth of innovative firms could have positive externality effects, especially in the Knowledge-Intensive Business Services sector which is associated with the growth of the entire economy.
\end{abstract}

\section{ARTICLE HISTORY}

Received 13 June 2014

In final form 9 January 2017

\section{KEYWORDS}

Employment growth; growth co-movements; sectoral taxonomy; industrial dynamics

\section{Introduction}

This paper investigates the co-movements of employment growth within and across industrial sectors and geographic regions in the entire Dutch economy, looking for regularities in the structure of sectoral employment growth rates. By impacting on the way resources are mobilized within the economy, the patterns of relations across technology-intensive sectors are powerful drivers of aggregate economic growth (Miozzo and Soete, 2001). Moreover, the shape of the distribution of sectoral growth rates provides additional evidence on the importance of intersectoral linkages for aggregate growth. As shown by Castaldi and Sapio (2008), it is characterized by fat tails and best described by a Laplace distribution, revealing that the complex interaction structure of microeconomic shocks may give rise to extreme positive and negative events of growth at the sectoral level. These dynamics are not evened out with further industrial aggregation of the data; instead, they are amplified by the correlations and feedback effects across firms and sectors. Castaldi and Sapio (2008)

CONTACT Marco Capasso marco.capasso@gmail.com

(4) Supplemental data for this article can be accessed here. http://dx.doi.org/10.1080/09535314.2017.1281232 
mention input-output relations as well as technological factors as potential supports for such intersectoral correlations.

Intersectoral linkages have indeed been studied from the point of view of the diffusion of innovations through knowledge or R\&D spillovers (De La Potterie, 1997; Verspagen, 1997) or supplier-customer relations using input-output tables (Miller and Blair, 2009). The focus on vertical relations is all the more relevant in the context of an increasing degree of outsourcing of some activities from the manufacturing to the business services sectors (Castellacci, 2008). It is then apparent that intersectoral linkages are multifaceted, and are commonly apprehended from a disaggregated point of view. Indeed, both the research on knowledge spillovers, which are often locally contained, and on input-output relations, which are usually defined at the 3-digit SIC sectoral level, require the use of finely disaggregated data.

As a complement to these detailed analyses, more evidence is needed about intersectoral dynamics at a regional level, for which input-output tables are generally not available. Studying co-movements of employment can instead be done at almost any level of spatial and sectoral aggregation. Because of our focus on labour market regions, we are limited in the level of sectoral disaggregation we can achieve (else we would end up with too many sector-region cells with zero employment, as for example in Forni and Paba, 2002). Thus our paper is a comprehensive study of co-movements of employment growth within and across labour market regions and broad industrial sectors.

Unlike the above-mentioned studies, we do not define precise channels of growth transmission in the same way input-output analyses can. Instead, we test whether aggregate relations of growth co-movement are observed at all, bearing in mind that they ultimately build on exchanges of goods and knowledge between heterogeneous firms. Still, by aggregating our firm-level data in different ways (using different taxonomies), we can understand which is the characteristic that counts in disaggregated data. Indeed, by looking at common influences obtained by all sectors having similar characteristics, we can connect a particular feature of a sector to a particular way its employment growth affects the rest of the economy (for instance, knowledge spillovers occurring purely because of geographic proximity, rather than input-output linkages through priced interactions). In this sense, adopting different taxonomies can highlight the appropriate characteristics of the regional economy that we should identify before suggesting policies.

Moreover, as pointed out by Beaudry and Schiffauerova (2009), the level of sectoral aggregation may affect (or not) the type of externalities which can be identified. It follows that, because "[p] olicy must necessarily operate at a general level" (Metcalfe, 1994, p. 932), it is important to verify that the relations existing across narrowly defined sectors hold when considering a broader definition of sectoral boundaries. In order to do so, we follow the approach by Castaldi (2009). She studies the relative contribution of different sectors to aggregate productivity growth by using a more aggregated 'sectoral innovationbased' taxonomy. Following this approach, the entire private sector is divided into eight groups, combining the typologies defined by Pavitt (1984) and Miozzo and Soete (2001) (in this paper, we refer to them as 'meso' typologies). ${ }^{1}$ Then, we construct a correspondence table matching our 'meso' groups to fewer more aggregated 'macro' sectors, on the basis

\footnotetext{
${ }^{1}$ In addition to Castaldi (2009), other analyses of intersectoral linkages at this level of aggregation have been performed by Laursen and Drejer (1999), Castellacci (2008) and Hauknes and Knell (2009).
} 
of theoretical considerations and empirical evidence from previous literature. As we will show, using different taxonomies of the meso-sectors, and thus different definitions of the macro-sectors, can not only inform on the dynamics of the value chain. It also gives insights into the relations between the manufacturing and services sectors, between the more or less-innovative ones, or between groups sharing similar labour skill requirements. For each taxonomy, we study the coevolution of the different macro-sectors in a vector autoregression (VAR) model, which allows us to assess whether and how employment growth in a macro-sector can predict employment growth in the same or other macro-sectors. Both intra-regional and inter-regional effects will be studied. This approach allows us to test alternative determinants of intersectoral employment linkages in a simple and flexible way.

Our contribution to the literature is the following. First, we test whether skill-led, innovation-led and supplier-customer-led employment linkages are still apparent when considering dynamics at a more aggregated level of analysis. Second, our methodology evaluates the relative importance of geographic versus sectoral similarities in explaining growth dynamics. Third, by expanding the list of possible intersectoral logics, we are not confined to the study of one specific type of linkages. By keeping an open mind about the sources of intersectoral growth co-movements, we aim at providing the policy-maker with a practical understanding of such dynamics, so that policies designed to stimulate economic activity can be targeted at the appropriate regional and sectoral levels.

We find that innovative sectors, especially the Knowledge-Intensive Business Services (KIBS), have a driving role in terms of employment growth within and across regions. Besides, employment growth linkages relate to the production process: except for information and communication technologies (ICT)-intensive sectors, similarity in labour skills is part of the explanation. In addition, we do not confirm a clear pattern along the value chain. Changes in downstream sectors do not trigger employment effects in upstream sectors, as input-output studies generally find.

By identifying co-movements of employment growth at the sector-region level, we advocate for a more targeted allocation of public funds towards innovative firms, especially in the KIBS service sector. Besides, we find that most sectoral linkages are apparent beyond the regional level, which also calls for a coordinated policy across territories and sectors.

The article is structured as follows. Section 2 presents the literature review. Sections 3 and 4 introduce our methodology and data. Our results are described and discussed in Section 5. Section 6 concludes.

\section{Literature review}

Our study is an empirical analysis of co-movements of employment growth, meant to reveal intersectoral linkages without imposing one particular theoretical scheme to justify the detected correlations. The literature informs us mostly about the sources and impacts of two intersectoral linkages: knowledge spillovers and supplier-customer relations (see about the former, e.g. De La Potterie, 1997; Verspagen, 1997; Los and Verspagen, 2002; Hauknes and Knell, 2009; Gehringer, 2012; and about the latter, see the empirical studies mentioned in Miller and Blair 2009). Moreover, the study of intersectoral patterns has seen the emergence of a diversity of sector typologies which can be used to evaluate the role of innovativeness, skill-relatedness or dynamics along the value chain in explaining sectoral dynamics. 


\subsection{Intra- versus intersectoral knowledge spillovers}

Theory predicts that positive knowledge externalities generate economic growth (Romer, 1986). Bringing this result to the data, however, requires to make explicit the mechanisms linking knowledge spillovers to growth, as well as which conditions facilitate the diffusion of such externalities. The seminal paper by Glaeser et al. (1992) has tested alternative theoretical predictions about the role of geographic and sectoral proximity as well as competition in enhancing technological spillovers. Their results are in line with the theory by Jacobs (1969) based on sectoral complementarity: intersectoral technological spillovers are more conducive to growth than intra-sectoral ones.

Following this first assessment, a stream of research has aimed to replicate these findings, with varying success (for reviews, see De Groot et al., 2009). These studies aim at testing whether knowledge spillovers are on average more apparent within or across sectors, using specialization versus variety indexes as indicators of intra- and intersectoral spillovers, respectively (see, e.g. Frenken et al., 2007).

Even if based on regional data, they may not control for all the different possible notions of proximity among the spatial units of the dataset. Indeed, employment growth of adjacent spatial units or regions sharing economic links, the same culture or local policies could be correlated (Bishop and Gripaios, 2010). Still, Frenken et al. (2007) find that taking spatial dependence in the form of the growth of neighbouring regions in their model into account does not improve or significantly alter their results.

\subsection{Patterns of sectoral linkages and sectoral typologies}

Although they demonstrate the role of intersectoral relations in explaining employment growth, the above-mentioned studies (Glaeser et al., 1992; De Groot et al. 2009) are not concerned with their patterns, that is, which sectors benefit from which other sectors' knowledge spillovers and dynamics. In that case, when evaluating intersectoral linkages, there is a trade-off between the use of highly disaggregated data which can inform about specific patterns of vertical relations, using input-output tables, and a wider categorization of sectors which describes the overall dynamics in the economy. Below, we describe both approaches and the related findings about patterns of sectoral linkages.

The approach by Forni and Paba (2002) intends to display sectoral interdependencies by constructing a 'spillover-matrix', based on the coefficients of specialization indexes constructed at a very disaggregated level (up to 3-digit NACE). They find that input-output relationships are good predictors of spillovers, while sectoral technological intensity is not. Conversely, Van Stel and Nieuwenhuijsen (2004) emphasize a distinction between industry and service sectors in terms of growth determinants. In the former, firm innovation capabilities drive growth, while in the latter the firm's ability to capitalize on knowledge spillovers from diverse sources does. Other works focus on the interrelations between industry and services, using input-output tables: Guerrieri and Meliciani (2005) evaluate that among manufacturing sectors, the demand for 'Financial, Communication, and Business' (FCB) services is higher in knowledge-intensive industries. This suggests that the similarity in knowledge intensity of these sectors might not be considered as less important than the common categorization between industry and services when predicting sector linkages, and that there can exist some complementarities between 
different sector typologies. When studying intersectoral linkages, manufacturing and services should therefore be disaggregated according to their technology or skill level (Bishop and Gripaios, 2010). Several ways to do this have been suggested in the literature.

Based on size, innovation patterns and sources of innovation, Pavitt (1984) divides firms in both manufacturing and services into four groups: scale-intensive, supplier-dominated, science-based and specialized-suppliers, where all services activities are included in the supplier-dominated category. This taxonomy is based on the assumed sectoral patterns of technical change: in the author's view, the way knowledge and innovation are produced and integrated in firms' production processes depends on sectoral characteristics. The Pavitt taxonomy provides insights on the relation between technological change and industrial structure. For example, size is an advantage in the scale-intensive sector, as are $R \& D$ capacities in the science-based group. The taxonomy is also suggestive of patterns of relations between sectors. ${ }^{2}$ In particular, intersectoral technological links are concomitant with the technological dependence of sectors as well as intersectoral learning processes.

Miozzo and Soete (2001) instead consider a different classification of services, and assign those firms to four other groups, namely the supplier-dominated services (SDS), scale-intensive physical networks services (PNS), information networks services (INS) and specialized-suppliers/science-based services (to which we refer as 'Knowledge-Intensive Business Services' or KIBS, following Castaldi, 2009). ${ }^{3}$ The authors focus on the technological linkages within services, and between services and manufacturing categories. Both the SDS and PNS's technologies originate from their suppliers in manufacturing, impacting on their ability to improve their product design (SDS) or their productivity (PNS). Instead, the INS and KIBS categories are more embedded in the service sector and are their own providers of technology (see Miozzo and Soete, 2001, Table 1, p. 161). Building on the same motivation as Miozzo and Soete (2001), Castellacci (2008) also integrates manufacturing and services within a unique taxonomy of sectoral patterns of innovation. Miozzo and Soete (2001), Guerrieri and Meliciani (2005) and Castellacci (2008) all point at a lack of research on the interrelations between services and manufacturing sectors. The Miozzo-Soete typology indeed enhances the role of innovation in services, especially through the development of knowledge- and technology-intensive sectors (INS and KIBS) and infrastructure services (PNS and INS). In particular, a reliable and cost-reducing infrastructure enhances productivity in both manufacturing and service firms (Castellacci, 2008). ${ }^{4}$

Although he describes a typology constructed from technological linkages, Castellacci (2008) emphasizes the role of vertical sectoral links based on supply and demand of inputs as a complement to knowledge exchanges. These vertical ties are in particular responsible for the diffusion of general-purpose technologies across sectors, as illustrated by the role of ICT in the development of knowledge-intensive services. As for Guerrieri and Meliciani (2005), KIBS firms are expected to replace the manufacturing sector as the core provider of strategic inputs to the entire system.

\footnotetext{
2 These patterns are described in more detail in Section 3.1.

${ }^{3}$ An alternative taxonomy of services according to their innovative processes has been suggested by Evangelista (2000).

${ }^{4}$ See Gallouj and Savona (2009) for a recent survey of the debate on innovation in services.
} 
The recent interest in the KIBS sector (see Drejer, 2002) goes beyond its role as intermediaries between services and manufacturing. As early emphasized by Den Hertog (2000) and Muller and Zenker (2001), KIBS play a major role in allowing the diffusion of knowledge throughout the economy. They do not merely transfer generic information but bring customized solutions to their clients (Guerrieri and Meliciani, 2005). Drejer (2002) also argues that business services can be considered as a production factor used by other industries bringing about positive externalities to user sectors. Still, it is unclear whether they should just be included within a large group of 'diffusers of knowledge' along with the manufacturing innovative sectors, or whether they contribute to the emergence of ICT general-purpose technologies.

\section{Methodology}

\subsection{Typologies}

We start from the original Pavitt-Miozzo-Soete taxonomy which defines eight mesosectors. ${ }^{5}$ In a second step, we group them into some 'aggregated' macro-sectors according to four different taxonomies. ${ }^{6}$ Following the first taxonomy, we have two macro-sectors, respectively manufacturing and services. The second classification considers two macrosectors in terms of innovativeness, and the third one distinguishes between Fordist, ICT and other firms. Finally, our fourth classification relates to the position of sectors along the value chain. We describe now in detail how we aggregate the meso-sectors into macrogroups, and what we expect regarding the employment spillover effects within and across the meso- and macro-sectors.

\subsubsection{Baseline: meso-sectors}

Sectoral knowledge and technological interrelations were already discussed in Pavitt's (1984) original work. In mapping sectoral patterns, he relied on data about the first use of innovations, that is, on whether they were embodied in capital or not. First, the Pavitt taxonomy allows one to assess vertical linkages such as the ones between suppliers and users of new products. In addition, the way knowledge and technology diffuse across Pavitt groups can be understood from the taxonomy:

[T] echnological linkages amongst sectors can go beyond transactions involving the purchase and sale of goods embodying technology. They can include flows of information and skills, as well as technological diversification into the main product areas of suppliers and customers.

(Pavitt, 1984, p. 364)

Figure 1 in Pavitt (1984, p. 364) sketches such technological linkages, where specializedsuppliers exchange innovations with science-based and scale-intensive firms, innovations in the science-based group flow towards supplier-dominated and scale-intensive sectors, while the latter also supply technology to supplier-dominated firms. ${ }^{7}$ The subsequent

\footnotetext{
${ }^{5}$ The qualification meso-sectors is made in relation with the lower level of aggregation as compared to what we call macrosectors. The Pavitt-Miozzo-Soete taxonomy is itself an aggregation of sectors at the 3-digit SIC level (further details about the aggregation can be found in Section 4.1).

${ }^{6}$ Note that our approach differs from a data-driven cluster-based approach as used by Hoen (2002).

7 The figure is reproduced in the online appendix, Figure A1.
} 
typologies which focus more on the service industry (Miozzo and Soete, 2001; Guerrieri and Meliciani, 2005; Castellacci, 2008) anticipate that within the service meso groups, the KIBS, on the one hand, and the PNS and INS, on the other hand, should drive the dynamics in the entire system. The former do so through their provision of tailored knowledge, and the latter through their cost-reduction effect.

\subsubsection{Classification 1: manufacturing and services}

The eight Pavitt-Miozzo-Soete meso-sectors are evenly distributed between manufacturing and services classes. According to Miozzo and Soete (2001), Guerrieri and Meliciani (2005) and Castellacci (2008), we should expect that the manufacturing macro-sector and the service macro-sector co-evolve.

Several mechanisms back our premise of the existence of employment relations across service and manufacturing sectors. First, Miozzo and Soete (2001) focus on technological linkages and the development of service innovation by technologically intensive service firms, for example, in KIBS. Such sectors could thus act as information network providers', for example by allowing firms in all sectors a better management of their data and information processes.

Guerrieri and Meliciani (2005), Castellacci (2008) and Corrocher and Cusmano (2014) instead emphasize the integration of manufacturing and service sectors through the outsourcing of service activities by manufacturing firms. Finally, Moretti (2010) argues that the employment growth of the tradable sector (comprising manufacturing firms) has a positive impact on the non-tradable sector (comprising service firms) by creating demand for locally produced and consumed services.

\subsubsection{Classification 2: innovativeness}

Innovations tend to be concentrated in a small cluster of sectors, which are characterized by fast growth (Fagerberg, 2004). On the one hand, positive effects of innovation on firm and sectoral performance are due to the returns of innovation and R\&D at the firm-level, especially important for the more dynamic firms (Coad and Rao, 2008; Capasso et al. 2015) in high-technology sectors. On the other hand, they are also related to the knowledge and technology acquired from other firms, like producers of capital goods or knowledgeintensive suppliers. ${ }^{8}$ The role of technology diffusion is essential to the understanding of the aggregate effects of innovation, since, both processes are 'mutually supporting' and 'inseparable' (Metcalfe, 1994, p. 939). Building on the insights of Pavitt (1984) and including, as we do, service industries, Hauknes and Knell (2009) provide measures of flows of knowledge and technology between user and producer-technology sectors in five OECD countries. They identify a particular role of specialized-supplier and scale-intensive industries for the production and diffusion of technology, and of high-tech service sectors for their function "as a kind of mediator or bridge builder between industry groups" (Hauknes and Knell, 2009, p. 468).

Hence, the growth effects of innovation diffusion, described in the seminal theoretical contributions by Nelson and Phelps (1966), may depend on the intensity and structure of flows of technology across sectors. As a consequence, technological stagnation can also

\footnotetext{
${ }^{8}$ Hauknes and Knell (2009) describe how input-output analysis has allowed one to measure such technology linkages.
} 
derive from issues associated to a low intensity of such flows (Geroski, 1992). By investigating the co-movements of employment growth between the more- and less-innovative macro-sectors, we can evaluate the employment relations across users and suppliers of technology.

We classify our meso groups as 'more' or 'less' innovative on the basis of empirical evidence. As observed by Souitaris (2002) using the Pavitt taxonomy, science-based (SB) and specialized-suppliers (SS) firms exhibit higher rates of technological innovation. ${ }^{9}$ Within services, we characterize KIBS as innovative, in accordance with the results by Den Hertog (2000). The inclusion of both KIBS and specialized-suppliers into the 'more innovative' class is confirmed by Castellacci (2008), who labels them as 'advanced knowledge providers'.

\subsubsection{Classification 3: skill-relatedness}

The first two classifications of macro-sectors consider linkages in terms of production process or in terms of technology diffusion. The two can be related by focusing on skill-relatedness. In their study of corporate diversification strategies, Neffke and Henning (2013) proxy the structure of cross-industry labour flows (movements of employees between industries) by a measure of skill-relatedness. They anticipate that industries sharing similar skill requirements would therefore be interconnected. On the one hand, the use of general-purpose technologies (Perez, 2010) involves a standardization of skills which facilitates labour movements across sectors. On the other hand, Fordist sectors also share a common standardized production process. By investigating interrelations within and between ICT and Fordist groups, we could evaluate whether skill-relatedness plays a role in accounting for co-movements of employment growth.

In addition to considering ICT as a factor of production requiring a particular set of labour skills, Perez (2010) discusses the transformative effect of such technological revolutions on the economic system:

While the new sectors expand to become the engines of growth for a long period, the technoeconomic paradigm that results from their use guides a vast reorganization and a widespread rise in productivity across pre-existing industries. (Perez, 2010, p. 189)

It follows that ICT-intensive sectors should be expected to drive growth in the rest of the economy, by reducing costs and enhancing the development potential in the 'old' (Fordist) industries.

Following Castellacci (2008), the ICT-intensive group comprises KIBS, science-based (SB), and INS. Fordist industries, however, include the PNS, scale-intensive (SI) and specialized-suppliers (SS) groups. Finally, supplier-dominated (SD) and SDS are labelled 'Others', as they neither fit the ICT nor Fordist categories.

\subsubsection{Classification 4: value chain}

Both demand and supply elements are important in explaining the competitive advantage of a firm (Porter, 1991). Sectoral linkages along the value chain are commonly evaluated using input-output tables (Miller and Blair, 2009). However, such data are generally

\footnotetext{
9 The innovation rate is measured by an index based on seven indicators drawn from the OECD 'Oslo Manual' (Souitaris, 2002).
} 
Table 1. Correspondence between Pavitt-Miozzo-Soete sectors and our four classifications (class 1: manufacturing/services; class 2: more/less innovative; class 3: ICT/Fordist; class 4: value chain (VC)).

\begin{tabular}{llllll}
\hline Meso-sector & Acronym & Class 1 & \multicolumn{1}{c}{ Class 2 } & Class 3 & Class 4 \\
\hline Scale-intensive & SI & Manuf & Less innovative & Fordist & VC 3 \\
Supplier-dominated & SD & Manuf & Less innovative & Others & VC 2 \\
Science-based & SB & Manuf & More innovative & ICT & VC3 \\
Specialized supplier & SS & Manuf & More innovative & Fordist & VC 1 \\
Supplier-dominated services & SDS & Services & Less innovative & Others & VC2 \\
Physical network services & PNS & Services & Less innovative & Fordist & VC 4 \\
Information network services & INS & Services & Less innovative & ICT & VC 4 \\
Knowledge-intensive business services & KIBS & Services & More innovative & ICT & VC 1 \\
\hline
\end{tabular}

unavailable at the level of labour market regions. Instead, following earlier contributions by Laursen and Drejer (1999), Castellacci (2008) and Hauknes and Knell (2009), we exploit the Pavitt classification to identify relatively 'upstream' versus 'downstream' sectors. Specialized-suppliers and KIBS (VC1) are referred to as most upstream, providing strategic inputs to the entire system (Guerrieri and Meliciani 2005). They are logically followed by the supplier-dominated and the SDS groups (VC2), which depend mostly on linkages with KIBS and specialized-suppliers. Closer to the final consumer are the providers of consumption-goods (scale-intensive and science-based groups, VC3). Finally, the infrastructure sectors (INS and PNS) would lie at the end of the value chain, as they represent the last stage of any production process and deal with distribution. They form our last group (VC4). Although this classification would certainly not fit all value chains at product levels, it allows us to posit as an additional, possibly meaningful classification in the empirical analysis below.

The correspondence between the meso and macro-sectors for all four classification criteria is displayed in Table 1.

\subsection{Model}

The aim of our analysis is to assess the correlation structure of employment growth rates across different sets of sectors and regions. We explain below how we devise the appropriate model.

Spatial econometric models are traditionally adopted to explicitly consider the influence of space on dependencies among variables, by means of a spatial weight matrix. It assigns a positive value to pairs of locations that are considered as 'neighbouring', and a zero value to the others (Anselin, 1988). Such models can include spatial lags in the dependent and independent variables, as well as in the error terms. Since different choices can be made regarding both the spatial structure of relations among variables as well as the weights in the weight matrix, finding the appropriate model specification is not easy. Besides, the interpretation of estimated coefficients is not straightforward. If the modeller does not want to be constrained by this set of assumptions, the spatial structure of inter-regional effects must be accounted for by alternative means.

Taking a different approach, we borrow a methodology from the firm growth literature. Coad (2010) studies the co-evolution of several firm growth variables using a reduced-form VAR model. The model is estimated through a system of regressions separately run on 
pooled cross-sectional data. Each variable of interest is a dependent variable in one regression and an independent variable in all the other regressions (Stock and Watson, 2001). The VAR model is chosen for its predictive features: by its estimation, we can grasp how growth in a variable anticipates growth in other variables, although such predictions do not necessarily correspond to causal structures connecting the variables. In our case, we study the coevolution of several sectors, where the dependent variable is the employment growth in a given sector and region in year $t$, and the independent variables are the growth rates in the same sector and in other sectors, in the same region and in neighbouring regions in the previous year.

The individual observations used in the empirical analysis thus consist of sector-region employment growth rates. Each employment observation is flagged with a meso-sectoral characteristic (one of the eight Pavitt-Miozzo-Soete groups) and a regional characteristic. After an initial meso aggregation, we construct macro-sector-region employment growth rates (where, for each separate model to be estimated, we use one of the four possible macro taxonomies outlined in Section 3.1), as the log difference of total employment within each macro-sector $(s=1, \ldots, S)$ in a given year $(t=1, \ldots, T)$ and region $(r=1, \ldots, R)$ :

$$
\mathrm{GROWTH}_{s r t}=\log \left(\mathrm{EMPL}_{s r t}\right)-\log \left(\mathrm{EMPL}_{s r t-1}\right) \text {. }
$$

The growth rate of employment in the neighbouring regions of $r$ is

$$
\mathrm{GROWTH}_{s N_{r} t}=\log \left(\sum_{x \in N_{r}} \mathrm{EMPL}_{s x t}\right)-\log \left(\sum_{x \in N_{r}} \mathrm{EMPL}_{s x t-1}\right),
$$

where $N_{r}$ is the set of neighbouring regions $x$ of $r$ and $\sum_{x \in N_{r}}$ EMPL $_{s x t}$ is the sum of employment in all regions belonging to the set $N_{r}$. We then use a VAR model to test whether employment growth in a particular region and macro-sector is predicted by the lagged growth in each macro-sector in the same region, as well as the lagged growth in each different macro-sector in the neighbouring regions.

Our dependent variable is the $S \times 1$ vector of sectorial growth rates $\mathbf{g}_{\mathbf{r t}}$ in region $r$, at time $t$, where $S$ represents the number of macro-sectors considered in each particular classification. Our regressors are the lagged values of $\mathbf{g}_{\mathbf{r t}}$ and $\mathbf{g}_{\mathbf{N}_{\mathbf{r}}}$ the latter being the vector of sectorial growth rates in the neighbouring regions. They are constructed as follows:

$$
\begin{aligned}
& \mathbf{g}_{\mathbf{r} t}=\left[\begin{array}{lll}
\mathrm{GROWTH}_{1 r t} & \mathrm{GROWTH}_{2 r t} & \cdots \mathrm{GROWTH}_{S r t}
\end{array}\right]^{\prime} \text {, } \\
& \mathbf{g}_{\mathbf{N}_{\mathbf{r}} \mathbf{t}}=\left[\mathrm{GROWTH}_{1 N_{r} t} \quad \mathrm{GROWTH}_{2 N_{r} t} \cdots \mathrm{GROWTH}_{S N_{r} t}\right]^{\prime} .
\end{aligned}
$$

The estimated model thus takes the following form:

$$
\mathbf{g}_{\mathbf{r} t}=\alpha+\beta \mathbf{g}_{\mathbf{r} t-1}+\gamma \mathbf{g}_{\mathbf{N}_{\mathbf{r}} \mathbf{t}-1}+B_{r}+\boldsymbol{\varepsilon}_{\mathbf{r} t},
$$

where $\beta$ is an $S \times S$ matrix of coefficients of the within-region impact of each macro-sector growth on the dependent variable. $\gamma$ is an $S \times S$ matrix of coefficients of the across-region impact (i.e. impact from neighbouring regions) of each macro-sector growth on the dependent variable. Finally, $\alpha$ is an $S \times 1$ vector of intercepts, $B_{r}$ is an $S \times 1$ vector of border 
region dummies and $\epsilon_{r, t}$ is an $S \times 1$ vector of disturbance terms. ${ }^{10}$ Following Coad (2010), Equation 3 is estimated using a 'reduced-form' VAR, where the $S$ individual regressions are performed independently using a Least Absolute Deviation model (LAD, or median regression). The LAD model is chosen given the non-Gaussian distribution of firm growth rates, as described in Section 4.2, which prevents us from using the OLS estimator.

After the first estimation, we consider two post-estimation steps. ${ }^{11}$ The first one is a robustness check: we include the second lag as well as the first one to allow for longer time spans for the interaction across sectors to occur. We focus in our interpretation and conclusion on the results which are significant and robust according to this first check. The second post-estimation step aims at defining the geographic scale of the relations previously identified. We estimate a second model in which, instead of considering the effect of the neighbouring regions on a given region, we consider the effect of all the other non-neighbouring regions on the same dependent variable. In other words, the same independent variables (i.e. the macro-sectoral growth rates) that are computed over the neighbouring regions in the baseline model are computed over all the other non-neighbouring regions in the second model. ${ }^{12}$ Relations observed between non-neighbouring region-sectors and the local region-sector can be interpreted as reflecting national patterns. Thus, if a relation detected as significant and robust in the estimation of the first model is estimated as significant and robust, and with the same sign also for the second model, we conclude that the effects of the neighbouring regions initially found are actually mirroring an effect of overall trends in the whole country. If this is not the case, then we interpret our detection of across-region relations as referring to specifically local neighbouring effects.

Our model has three main limitations. First, we do not consider contemporaneous effects (i.e. occurring within less than one year) across sectors or regions. A full structural identification of the VAR would be possible only by imposing theoretical assumptions or by having the availability of a larger dataset. In this paper, we adopt a simple econometric model, which is valid for predictive purposes (the relations we find do indeed represent recurrent temporal sequences of growth across sectors). Our study provides clues for causal relations, in that the temporal patterns we retrieve bring forward possible interpretations of the observed reality. The data-driven approach followed in this study limits us to the discovery of temporal patterns, and to theoretical suggestions formulated expost. An examination of all the possible causal relations, which are consistent with the temporal patterns retrieved from our data, would be beyond the scope of this paper. By discarding contemporaneous links, we come close to the approach of Giacomini and Granger (2004) who introduce a Space-Time Autoregressive (ST-AR) model. A ST-AR $(p, q)$ model considers both temporal lags $(p)$, and spatial lags $(q)$. We depart from the original ST-AR formulation to allow for a vector form of the autoregression, and consider several variables (each one being the growth rate in a particular macro-sector) for each region and year.

A second limit of our methodology lies in not considering the panel nature of the data. We do not take into account the unobserved characteristics of regions. These can,

\footnotetext{
10 Given our focus on neighbouring regions, foreign neighbours (for which data are not available) might also have an effect on the employment dynamics of the regions situated at the border (included in our dataset). In order to address this issue we flag the border regions by using a dummy variable. Note however that such a 'border dummy' only controls for the difference in average growth of these regions as compared to the rest of the country.

${ }^{11}$ At any level of sectoral disaggregation, multicollinearity does not seem to affect our results.

12 For this second model, we apply the same robustness check using the second lag, as for the first model.
} 
in principle, be present in more than one cross-sectional wave. Allowing for the existence of such characteristics would require either estimating Panel VAR models, in its original (Love and Zicchino, 2006) or structural (Pedroni, 2013) version, or including spatial neighbouring effects within the same PVAR models. The latter would entail methodological advances in spatial econometrics that go beyond the scope of this paper. Instead, we believe that by estimating our model directly on employment growth rates (rather than on employment levels), the influence of region-specific omitted unobservable variables, and in particular of those unobservable components that affect regional employment levels, is attenuated. Besides, because our model includes a lagged dependent variable, adding sector-region fixed effects would bring to biased estimation results (see Nickell, 1981, for a general description of the bias and Coad, 2010, for its discussion within a VAR framework).

A third limitation regards the interpretation of the coefficients, given the possible existence of indirect (neighbouring) effects as described by Lesage (2008). In that case, the autoregressive coefficient (i.e. the effect of within-region characteristics on the dependent variable) is not enough to assess the overall (direct + indirect) impact of a change in the region-regressor on the dependent variable. This issue undermines our ability to interpret the coefficients as 'average total effects', that is, the overall effect including the feedbacks through the other regions. It would pose a real problem in case of feedback effects of different signs (e.g. the within-region coefficient and the neighbouring region coefficient presenting different signs). However, as we will show in the results, we do not encounter such case in our data.

\section{Data and statistics}

\subsection{Data}

Our empirical investigation uses an annual dataset of Dutch firms, the Business Register (BR), provided by Statistics Netherlands, for the years 1994-2005. It contains the entire population of Dutch firms which are fiscally registered in the Netherlands, including self-employment (firms with zero employees). We retrieve for each firm the number of employees, the fiscal address and the sector of activity at the 3-digit level. ${ }^{13,14}$

The correspondence between 3-digit SIC sectors and the Pavitt-Miozzo-Soete taxonomy is taken from Castaldi (2009) with one exception: SIC classes 334 and 335 (Optical and other instruments) are moved from the scale-intensive to the specialized-suppliers group, based on the description of this particular sector by Buerger and Cantner (2011). ${ }^{15}$

We construct our spatial unit of observation at the NUTS 3 level (also called COROP regions, following a Dutch acronym) from the fiscal addresses of firms. The 40 COROP regions are constructed by the Dutch statistical office by breaking down the 12 provinces of the Netherlands into 40 labour market regions. Within the relatively small NUTS 3 regions, face-to-face interactions can be organized and activities are often clustered around a city or group of cities. This particular choice is also supported by the findings of Van Stel and

\footnotetext{
${ }^{13}$ Firms with multiple plants thus have only one address, although production sites can be actually dispersed.

${ }^{14}$ The database is even more precise as it informs on the firm's sector at the 5-digit level according to the Dutch sectoral classification (SBI), but we aggregate this information up to three digits.

15 The resulting correspondence table is shown in the online appendix.
} 
Nieuwenhuijsen (2004). They provide evidence of inter-regional spillovers across NUTS 3 regions in the Netherlands, and against country-wide effects.

The final dataset of one-year employment growth rates identifies observations along three dimensions: sector, year and region. We start from 12 years of available data (1994-2005), out of which we lose the first one in order to compute growth rates, and a second one due to the lagged employment growth variable. For each of the remaining 10 years, we have 40 COROPs, which should therefore leave us with 400 COROP-year observations per sector. However, the final count of the observations is reduced by two factors. First, for the most disaggregated typology, it may happen that there are regions without any employee in a given sector-year, and the corresponding observations are thus removed. Second, we remove outliers, identified as absolute values of the employment growth rates above 0.4. ${ }^{16}$ As pointed out by Bishop and Gripaios (2010), outliers are more frequent in the case of smaller sector-regions units, where small changes in employment can lead to large changes in terms of growth rates. Ultimately, we get between 324 and 338 observations in our samples at the meso-sectoral level, and between 378 and 396 observations at the macro-sectoral level.

\subsection{Descriptive statistics}

Information about sector size and its evolution across time reflects some structural changes in the Dutch economy over the period: the manufacturing sector has been shrinking, while services have expanded. ${ }^{17}$ However, the standard deviation in the latter group is very large (more than twice the median value), which reflects higher heterogeneity in the weight of services across regions. The median regional employment share is higher for less innovative, Fordist, and infrastructure (VC4) groups, while the median regional employment growth is higher in the more innovative, ICT and 'top of the value chain' sectors.

As displayed in Figure 1, the density plot of the unconditional sector-region employment growth rates, shown with a logarithmic vertical axis, presents a similar shape at the different levels of aggregation. Moreover, it resembles a Laplace distribution, as evident from the characteristic tent shape. Indeed, fat tails are observed at the meso-level (KIBS), as well as at the macro-level (ICT, Manufacturing). Besides, the three plots show that both the location and scale of the Laplace distributions are common to the three sectors presented in Figure 1.

\section{Results and discussion}

\subsection{Results by group}

\subsubsection{Meso-sectors}

We start our empirical analysis with the study of employment growth patterns among the eight groups of the Pavitt-Miozzo-Soete typology. For each meso-sector and region, we

\footnotetext{
${ }^{16}$ To facilitate the readability of our results, we have chosen a common threshold value across sectors and years, and symmetric for the right and left sides of the employment growth empirical distributions. The chosen value allows us to exclude growth events which clearly lie outside of the body of the empirical distributions, while keeping the main body of the distribution still within the analysis range.

17 Descriptive statistics at the macro-sectoral level are available in Table A2 of the online appendix.
} 
Figure 1. Kernel density distribution of the unconditional growth rates. Top: Manufacturing; center: ICT; bottom: KIBS. Note the log scale on the $y$-axis.

\section{1.a Manufacturing}

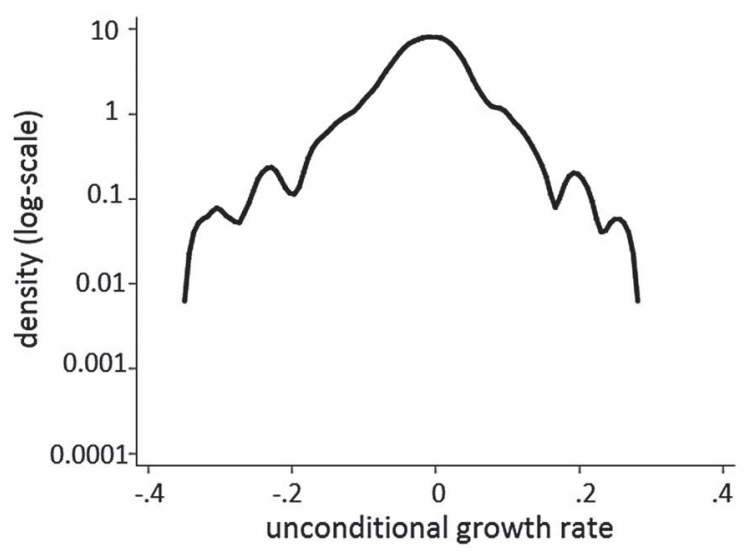

1.b ICT

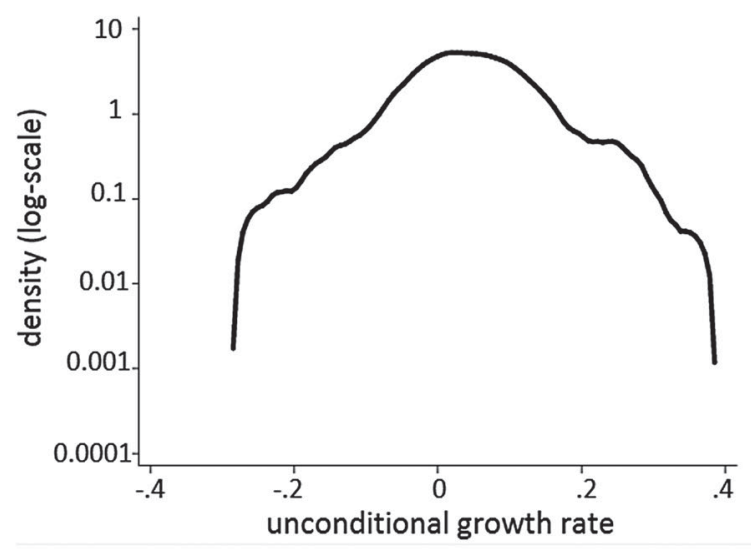

1.c KIBS

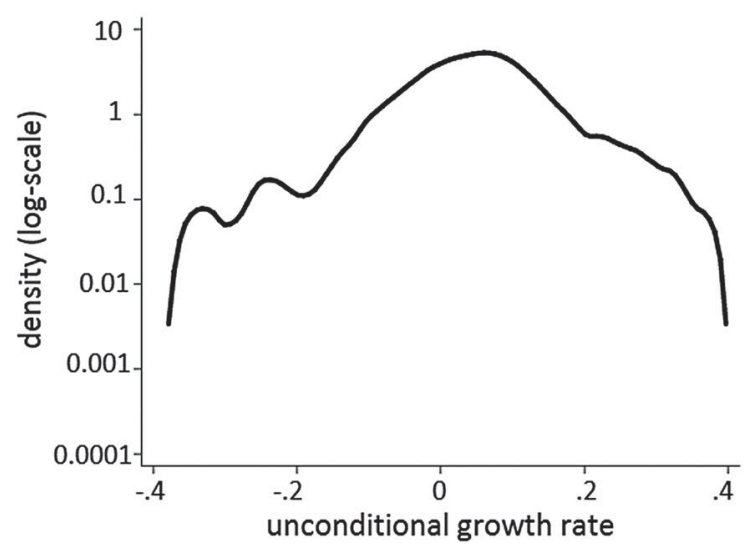


Table 2. Meso-sectors.

\begin{tabular}{|c|c|c|c|c|c|c|c|c|}
\hline & $\begin{array}{c}\text { SI } \\
\text { (1) }\end{array}$ & $\begin{array}{l}\text { SD } \\
\text { (2) }\end{array}$ & $\begin{array}{l}\text { SB } \\
\text { (3) }\end{array}$ & $\begin{array}{l}\text { SS } \\
\text { (4) }\end{array}$ & $\begin{array}{l}\text { SDS } \\
(5)\end{array}$ & $\begin{array}{l}\text { PNS } \\
\text { (6) }\end{array}$ & $\begin{array}{l}\text { INS } \\
\text { (7) }\end{array}$ & $\begin{array}{c}\text { KIBS } \\
(8)\end{array}$ \\
\hline $\mathrm{SI}-1$ & -0.061 & -0.014 & -0.109 & 0.006 & 0.046 & 0.008 & 0.001 & 0.004 \\
\hline SI neighb $t-1$ & -0.119 & 0.021 & 0.045 & -0.003 & -0.012 & 0.076 & 0.054 & -0.096 \\
\hline $\mathrm{SD} t-1$ & 0.031 & $-0.21^{* *}$ & 0.054 & $0.094^{*}$ & 0.009 & -0.007 & $0.099 *$ & 0.051 \\
\hline SD neighb $t-1$ & 0.13 & -0.013 & 0.045 & -0.109 & 0.023 & 0.029 & 0.159 & 0.186 \\
\hline$S B t-1$ & 0.005 & 0.026 & $-0.135^{* *}$ & -0.001 & -0.025 & 0.021 & 0.039 & 0.053 \\
\hline$S B$ neighb $t-1$ & 0.032 & -0.011 & -0.043 & 0.016 & -0.005 & -0.026 & -0.015 & 0.039 \\
\hline SS $t-1$ & 0.064 & 0.001 & 0.038 & 0.030 & 0.008 & 0.003 & $0.088^{*}$ & 0.027 \\
\hline SS neighb $t-1$ & $0.19 * *$ & 0.068 & 0.126 & 0.129 & $0.097^{* *}$ & 0.054 & 0.163 & 0.037 \\
\hline SDS $t-1$ & 0.056 & -0.016 & -0.042 & -0.111 & 0.035 & 0.019 & -0.150 & 0.012 \\
\hline SDS neighb $t-1$ & 0.119 & 0.11 & -0.253 & 0.006 & $0.178^{* *}$ & 0.078 & 0.143 & 0.273 \\
\hline PNS $t-1$ & -0.001 & -0.04 & 0.128 & -0.041 & $0.137^{* * *}$ & 0.053 & 0.049 & $0.202^{*}$ \\
\hline PNS neighb $t-1$ & -0.14 & 0.146 & 0.215 & 0.120 & $0.136^{* *}$ & $0.221^{* * *}$ & 0.017 & 0.186 \\
\hline INS $t-1$ & -0.037 & 0.02 & 0.016 & -0.015 & 0.018 & 0.001 & $-0.106^{*}$ & -0.001 \\
\hline INS neighb $t-1$ & 0.061 & 0.022 & 0.033 & -0.016 & -0.014 & -0.019 & 0.044 & 0.013 \\
\hline $\mathrm{KIBS} t-1$ & 0.028 & -0.011 & 0.018 & -0.005 & 0.033 & 0.018 & -0.079 & -0.060 \\
\hline KIBS neighb $t-1$ & 0.022 & $0.117^{*}$ & -0.036 & 0.126 & 0.015 & $0.091^{* *}$ & $0.285^{* * *}$ & $0.161^{* *}$ \\
\hline Border & -0.003 & 0.006 & -0.007 & -0.006 & -0.003 & -0.005 & -0.009 & -0.006 \\
\hline Pseudo $R^{2}$ & 0.043 & 0.065 & 0.0337 & 0.0344 & 0.1746 & 0.1429 & 0.0886 & 0.1664 \\
\hline Nb. obs & 337 & 336 & 325 & 335 & 339 & 337 & 334 & 337 \\
\hline
\end{tabular}

Note: Baseline model (robust results in bold font).

investigate the impact of the lagged growth of the same sector and the impact of the lagged growth of each of the other seven sectors, both in the same region and in the neighbouring regions. In Table 2, coefficients and their significance levels are presented. Results significant at the $10 \%$ level in the baseline specification as well as when including a second lag are considered robust and shown in bold font in Table $2 .^{18}$

Are the predictions from Pavitt (1984) confirmed in our analysis? In other words, do technological linkages among manufacturing groups translate into co-movements of employment growth? According to Pavitt (1984), supplier-dominated employment growth (column 2) should be driven by the dynamics in the science-based and scale-intensive sectors. Our results are at odds with this prediction; instead, the coefficient of KIBS growth in neighbouring regions is positive, significant and robust, as is its impact on the Information Network Services (INS) sector (column 7). This is evidence that expansion in the knowledge-intensive services industry is complementary to infrastructure growth, especially if the processes concern similar degrees of knowledge intensity.

Other results are to be noted, although with more caution since they are no longer valid once we add a second lag to the analysis as a robustness test. KIBS growth is also positively related to growth in the PNS sector, confirming the prevalent role of this sector on the rest of the economy. ${ }^{19}$ Positive employment relations are also observed to originate from the supplier-dominated sector (in the same region) towards the specialized-supplier sector. This could be seen as a demand-driven vertical relation from users to suppliers of intermediate goods; however, the result is not in line with Pavitt (1984). The supplier-driven

\footnotetext{
18 The value of coefficients and significance levels of the robustness test including the second lag are available from the authors upon request. Our results, for all taxonomies, are also graphically summarized in Figure A3 of the online appendix.

19 The causal relations between KIBS and the rest of the economy are further studied in Brenner et al. (2015), in the case of Germany.
} 
Table 3. Manufacturing and services.

\begin{tabular}{lcc}
\hline & Manufacturing & Services \\
\hline Manuf $t-1$ & -0.077 & 0.016 \\
Manuf Neighb $t-1$ & 0.027 & 0.072 \\
Services $t-1$ & 0.057 & $\mathbf{0 . 1 7 5}^{* * *}$ \\
Services Neighb $t-1$ & 0.073 & $\mathbf{0 . 2 5}^{* * *}$ \\
Border & 0.004 & -0.002 \\
Pseudo $R^{2}$ & 0.0117 & 0.1669 \\
Nb. obs & 396 & 393 \\
\hline
\end{tabular}

Note: Baseline model (robust results in bold font).

dynamics are instead observed from specialized-suppliers towards the scale-intensive sector (column 1) as well as SDS, at the inter-regional level (column 5) and infrastructure network services at a regional level (column 7). The science-based sector (column 3) stands out from the rest, because its employment dynamics are not explained by any of the other sectors.

The conjecture that the interrelation between services sectors is partly explained by technology elements is confirmed by the fact that physical networks are especially important to predict the growth of SDS. Indeed, these include the sector of hotels and restaurants, which is typically labour- and low-skilled intensive. In comparison with the dynamics within manufacturing, it appears that linkages within services are more technologydriven. Finally, we find negative effects for the conditional autocorrelation of intra-regional employment growth rates in the supplier-dominated, science-based and information network services groups.

In our second model, we evaluate the impact of the growth in all the other nonneighbouring regions on a sector-region, instead of the neighbouring regions alone In the case of sectoral interrelations at the meso-level, the findings from our two different specifications are only partly overlapping. ${ }^{20}$ The positive impact of the KIBS sector is enlarged (combining both models, only the scale-intensive and specialized-supplier groups do not respond to previous KIBS growth), while some of the other effects are not confirmed and could therefore be interpreted as localized relations. In turn, KIBS growth is itself predicted by PNS growth at the national level. The role of infrastructure sectors should therefore be evaluated more in depth, as we present below. The role of backward-demand linkages emanating from the scale-intensive or the SDS sectors are not captured by our specification, neither at the local nor the national levels. Instead, supplier-dominated sectors do exert a positive pressure on their suppliers, that is, the specialized-supplier sector.

Finally, the border dummy is not significant in any of the models. Such lack of effect of the border dummy is also supported by empirical evidence comparing the diffusion of technological spillovers within and across borders. Indeed, Laursen and Meliciani (2002) show that inter-firm learning of tacit knowledge is more developed between firms within a similar country. Similarly, Peri (2005) finds that country borders significantly hamper patent citation flows.

\footnotetext{
${ }^{20}$ A summary of the results from the different model specifications can be found in Tables A3-A7 of the online appendix.
} 
Table 4. Innovativeness.

\begin{tabular}{lcc}
\hline & More innovative & Less innovative \\
\hline More innov $t-1$ & -0.038 & 0.021 \\
More innov neighb $t-1$ & $\mathbf{0 . 2 1 9 ^ { * * * }}$ & $\mathbf{0 . 0 7 9 ^ { * * }}$ \\
Less innov $t-1$ & 0.162 & 0.007 \\
Less innov neighb $t-1$ & $\mathbf{0 . 3 2 5 ^ { * * }}$ & $\mathbf{0 . 2 5 9 ^ { * * * }}$ \\
Border & -0.012 & -0.005 \\
Pseudo $R^{2}$ & 0.1036 & 0.0892 \\
Nb. obs & 382 & 382 \\
\hline
\end{tabular}

Note: Baseline model (robust results in bold font).

\subsubsection{Manufacturing and services}

Our first set of results is in line with the predictions from the literature on technological spillovers (Miozzo and Soete, 2001; Guerrieri and Meliciani, 2005; Castellacci, 2008): we observe linkages between meso-sectors in the service industry and other meso-sectors in manufacturing. However, at this point we cannot generalize the findings as evidence of a co-evolution of manufacturing and services sectors. Thus, we proceed by formally testing this statement and measuring the impact that both macro-groups have on each other. Table 3 clearly contradicts this hypothesis: only the positive reinforcement dynamics within services, both at the intra-regional and inter-regional levels, is supported by our findings. Instead, when using our second model specification, we find a positive impact of the national trend in growth in services on manufacturing. Thus, the relation between the two macro-sectors is not driven by manufacturing demand for services, but by the increased availability of services to manufacturing firms, at a nationwide level. The fact that the relations between services and manufacturing are quite weak when using the aggregated typology also informs us about the role of specific service meso-sectors as bridges between the manufacturing and service industries, as also emphasized by Hauknes and Knell (2009). Given the higher growth rate of employment in services over the period under consideration, the observed positive relation has supported the performance of manufacturing firms.

\subsubsection{Innovativeness}

In our data, sectors characterized by a higher rate of innovativeness (the KIBS, SS and SB groups) show a higher median growth rate of employment. Our next exercise is thus about the impact that those dynamic sectors may have on the rest of the economy. Taken separately (Section 5.1.1), it is the growth in KIBS which is mainly predictive of employment expansion in other sectors; SS too but to a lower extent, while SB is not. Taken together, the expected diffusion effect is indeed observed; both when considering neighbouring regions (see Table 4) and all the other regions. Patterns of growth in the group of innovators anticipate the dynamics in the rest of the economy. However, we also observe feedback effects from the less innovative to the more innovative sectors at the local and nationwide levels, as put forward in the 'systems of innovation' literature (Lundvall, 2009). Besides these linkages across macro-groups, the autocorrelation coefficients are also positive, and large in magnitude. In conclusion, there is a 'clustering' effect among sectors characterized by similar levels of innovativeness, and some positive feedback mechanisms are also at play across these two clusters. 
Table 5. Skill-relatedness.

\begin{tabular}{lccc}
\hline & Fordist & ICT & Others \\
\hline Fordist $t-1$ & -0.034 & $0.181^{* *}$ & 0.091 \\
Fordist neighb $t-1$ & $\mathbf{0 . 2 9 2}^{* * *}$ & $0.383^{* *}$ & $\mathbf{0 . 2 2 4 ^ { * * }}$ \\
ICT $t-1$ & $0.053^{* *}$ & -0.065 & 0.015 \\
ICT neighb $t-1$ & 0.003 & 0.083 & 0.060 \\
Others $t-1$ & 0.041 & 0.007 & $-\mathbf{0 . 1 6 6 ^ { * * }}$ \\
Others neighb $t-1$ & $\mathbf{0 . 1 4 8 ^ { * * }}$ & $\mathbf{0 . 3 4 0 ^ { * * }}$ & $0.221^{* * *}$ \\
Border & -0.004 & 0.005 & -0.004 \\
Pseudo $R^{2}$ & 0.1051 & 0.1025 & 0.0986 \\
Nb. obs & 386 & 387 & 388 \\
\hline
\end{tabular}

Note: Baseline model (robust results in bold font).

Table 6. Value chain.

\begin{tabular}{|c|c|c|c|c|}
\hline & VC1 & VC2 & VC3 & VC4 \\
\hline $\mathrm{VC} 1 t-1$ & -0.068 & 0.044 & 0.068 & 0.006 \\
\hline VC1 neighb $t-1$ & $0.202^{* * *}$ & $0.010^{* * *}$ & 0.076 & $0.109^{* *}$ \\
\hline $\mathrm{VC} 2 t-1$ & -0.026 & $-0.184^{* * *}$ & $0.106^{*}$ & -0.004 \\
\hline VC2 neighb $t-1$ & $0.446^{* * *}$ & $0.224^{* * *}$ & 0.044 & $0.181^{*}$ \\
\hline VC3 $t-1$ & 0.048 & -0.029 & -0.052 & -0.001 \\
\hline VC3 neighb $t-1$ & -0.039 & -0.003 & -0.036 & 0.043 \\
\hline VC4t-1 & 0.106 & 0.066 & 0.009 & 0.022 \\
\hline VC4 neighb $t-1$ & $0.200^{* *}$ & $0.119^{*}$ & -0.124 & 0.138 \\
\hline Border & -0.002 & -0.006 & 0.001 & -0.001 \\
\hline Pseudo $R^{2}$ & 0.1425 & 0.1059 & 0.0235 & 0.0998 \\
\hline Nb. obs & 380 & 382 & 380 & 380 \\
\hline
\end{tabular}

Note: Baseline model (robust results in bold font).

\subsubsection{ICT and Fordist sectors}

Results about sectoral dynamics according to the third macro-classification are displayed in Table 5. The hypothesis of a higher interconnectedness among sectors sharing similar skills requirements (i.e. within the ICT or the Fordist group) is only partially validated. If we do find positive intra-sectoral and inter-regional effects within the Fordist sector (and the residual sector, 'Others'), the ICT sector does not fall into a similar pattern. Instead, we observe linkages across the macro-groups. In particular, growth in the ICT sector is highly correlated with lagged growth in the rest of the economy, where both coefficients of Fordist and Others sectors in neighbouring regions (and within regions in the case of the Fordist sector) are significant and positive. There is also a small intra-regional feedback effect from the ICT to the Fordist sector. In any case, these results are at odds with the idea that ICT-intensive sectors, by making new production techniques available, have a significant impact on employment growth in the more 'traditional' sectors (Perez, 2010).

\subsubsection{Value chain}

The last set of results concerns the employment co-movements along the value chain. We expect to observe stronger linkages across sectors which are closely related in the value chain, although the direction of the relations is not determined ex-ante (both demandpull and supply-push effects could be inferred from positive significant coefficients). One possible exception regards the infrastructure sector (our VC4 group), which could 
influence relatively distant sectors through its cost-reduction effect at all levels of the value chain.

The estimated effects (displayed in Table 6) do not support a linear spillover dynamic along the value chain, to say the least. If upstream groups (VC1 and VC2) are closely interconnected at the inter-regional level, consumption-good firms (SB and SI in the VC3 group) are almost completely isolated, only positively affected at the local level by VC2 (supplier-dominated) firms. Finally, at the end of the value chain, the infrastructure sector (PNS and INS, our VC4 group) is positively impacted by employment growth from VC1 and VC2, and enhances the growth of these two sectors. However, some of the linkages at the inter-regional level are actually mirroring national trends, since they are present in both models (using alternatively neighbouring regions or the other non-neighbouring regions). In particular, the driving push of upstream sectors is robust to the inclusion of the second lag and present at all levels of aggregation.

\subsection{General discussion}

Overall, our results show that both intra- and intersectoral co-movements of employment growth are very common and are mostly extended to the neighbouring regions. Still, the intra-sectoral effects are solely present within the same region: conditional autocorrelation of employment growth is only observed in the Services sector. This suggests that the omitted variable bias, which we overlook by not using sector-region fixed effects, is in fact limited.

The inter-regional dynamics do not always overlap with the national trend, as evident from the comparison between the baseline and the 'other regions' specifications. The spatial distribution of sectors therefore matters for the pattern of employment co-movements: the dynamics in the SDS, Fordist and upstream sectors only follow employment changes in the neighbouring regions. Instead, significant relations at the national level are mostly also detected when evaluating the impact of neighbouring regions.

Our methodology does not assume a particular type of linkage a priori, but it suggests their existence only after an empirical analysis of the regional and sectoral changes in employment. Our results hint at the relative importance of technological (through knowledge, innovation or general-purpose technology diffusion), and production (supplier-customer relationships, dynamics along the value chain) linkages. The answer is not clear-cut: we both find that some types of technological linkages as well as some types of production-related ones can serve to predict employment growth.

In relation with technology, we observe clustering effects (positive intra-sectoral impacts) within groups of sectors sharing similar levels of innovation rates. These results are in line with dynamics detected across service meso-sectors, where we observe a connection between low-tech services (PNS and SDS) as well as between high-tech ones (KIBS and INS). Also, the innovation diffusion seems to bring employment effects, while the diffusion of general-purpose technology does not.

In relation with the production process, we expected to find elements related to the increased interconnection of manufacturing and services, with the outsourcing of some activities previously managed by manufacturing firms to the service sector. At the most aggregated level, we find that manufacturing and services have largely independent dynamics. However, at the more disaggregated level (when considering Pavitt-Miozzo-Soete 
sectors), some interactions emerge: the KIBS group predicts growth dynamics of some of the manufacturing groups (SD). Finally, our results suggest that infrastructure follows growth from the top of the value chain.

When comparing the patterns of employment co-movements among meso-sectors, and among the macro ones, the results do not perfectly match. Indeed, dynamics at the macrolevel cannot be simply inferred from more disaggregated elements. Two reasons behind the mismatch could be respectively: the higher proportion of noise in more disaggregated data, and the existence of interaction effects between meso-level sectors. First, the meso-level analysis suffers from data limitations which are partially corrected with aggregation. For example, the number of employees in each Pavitt-Miozzo-Soete group can be subject to important variations across NUTS 3 regions. As a consequence, growth rates of employment could be more volatile (and dependent on idiosyncratic variations) in some sector-region couples than others. Second, results from the meso-level analysis may not retrieve additional interaction effects among the meso groups, which could lead, for instance, to a significant influence of the lagged growth in one meso-sector only when coupled with the lagged growth in other meso-sectors. Conversely, if such complementarities did not exist, we should see consistency between our findings from alternative typologies: knowing which meso-sectors are included in each macro-group and looking at Table 2 would be enough to predict all the other results.

Let us consider for example the role of KIBS. Its driving role is evident from Table 2: almost all the other meso groups are positively influenced by growth dynamics in this sector. However, depending on which other sectors are 'paired' with KIBS, such driving role is or is not confirmed. When combining KIBS, SB and SS, we find that this group of innovators positively influences the less-innovative ones. However, note that SB does not predict growth in any of the other sectors when taken separately. This could mean that the effect of KIBS is so strong that it is not diluted at this macro-level, or be seen as evidence of complementarity effects. When paired again with SB, but INS instead of SS to form the ICT macro-sector, KIBS no longer matters for the growth of the rest of the economy. Finally, the upstream sector formed by KIBS and SS (VC1) also has a positive impact on two of the other value chain groups. Therefore, we could conclude that positive complementarities emerge when KIBS and SS firms are present in the same region.

\section{Concluding remarks}

In this paper, we evaluate co-movements of employment growth within and between regions, and within and between sectors. We construct a correspondence table matching eight Pavitt-Miozzo-Soete groups to macro-sectors on the basis of theoretical considerations and empirical evidence from the previous literature. For each typology, we study the coevolution of the different sectors in a VAR model, which allows us to assess whether and how growth in a macro-sector, in a given region, can predict growth in the same or other macro-sectors, in the same or in other regions. Our findings bring to light the inter-regional nature of intra- and intersectoral linkages, as well as the existence of complementarities between sectors. In particular, if innovation diffusion is present, clustering effects within technologically similar groups are also observed. In turn, other theoretical predictions regarding the pushing role of ICT-intensive sectors are not confirmed with our methodology. 
By identifying co-movements of employment growth at the sector-region level, a more targeted allocation of public funds towards innovative firms can be designed for their positive externality effects, especially in the KIBS service sector. Besides, the fact that for some macro-sectors sectoral linkages are apparent beyond the regional level calls for a coordinated policy across territories. This also means that local and sectoral policy evaluations should include the spillover effects on other industries and regions.

Further research needs to complement our findings along different dimensions. First, data harmonization among European countries could make alternative estimation procedures which retrieve the causality of the process feasible. Moreover, with a larger time dimension, we could test whether the pattern of sectoral linkages is similar when considering longer time lags, allowing for intersectoral effects to unfold in time.

\section{Acknowledgements}

We thank Ron Boschma, Giulio Bottazzi, Davide Fiaschi, Andrea Morrison, Frank van Oort, two anonymous referees and the participants at the Economic Geography seminar (2 May 2012, Utrecht University), and at the PRIN final workshop (24 October 2013, Rome) for comments and discussions.

\section{Disclosure statement}

No potential conflict of interest was reported by the authors.

\section{References}

Anselin, L. (1988) Spatial Econometrics: Methods and Models (Vol. 4). Dordrecht, Springer.

Beaudry, C. and A. Schiffauerova. (2009) Who's Right, Marshall or Jacobs? The Localization Versus Urbanization Debate. Research Policy, 38, 318-337.

Bishop, P. and P. Gripaios. (2010) Spatial Externalities, Relatedness and Sector Employment Growth in Great Britain. Regional Studies, 44, 443-454.

Brenner, T., M. Capasso, M. Duschl, K. Frenken and T. Treibich. (2015) Causal Relations Between Knowledge-intensive Business Services and Regional Employment Growth (LEM Working Paper 2015/27, Scuola Superiore Sant'Anna, Pisa).

Buerger, M. and U. Cantner. (2011) The Regional Dimension of Sectoral Innovativeness: An Empirical Investigation of Two Specialized Suppliers and Two Science-based Industries. Papers in Regional Science, 90, 373-393.

Capasso, M., T. Treibich and B. Verspagen. (2015) The Medium-term Effect of R\&D on Firm Growth. Small Business Economics, 45, 39-62.

Castaldi, C. (2009) The Relative Weight of Manufacturing and Services in Europe: An Innovation Perspective. Technological Forecasting and Social Change, 76, 709-722.

Castaldi, C. and S. Sapio. (2008) Growing Like Mushrooms? Sectoral Evidence from Four Large European Economies. Journal of Evolutionary Economics, 18, 509-527.

Castellacci, F. (2008) Technological Paradigms, Regimes and Trajectories: Manufacturing and Service Industries in a New Taxonomy of Sectoral Patterns of Innovation. Research Policy, 37, 978-994.

Coad, A. (2010) Exploring the Processes of Firm Growth: Evidence from a Vector Auto-regression. Industrial and Corporate Change, 19, 1677-1703.

Coad, A. and R. Rao. (2008). Innovation and Firm Growth in High-tech Sectors: A Quantile Regression Approach. Research Policy, 37, 633-648.

Corrocher, N. and L. Cusmano. (2014). The 'KIBS Engine' of Regional Innovation Systems: Empirical Evidence from European Regions. Regional Studies, 48, 1212-1226. 
De Groot, H. L. F., J. Poot and M. J. Smit. (2009) Agglomeration, Innovation and Regional Development: Theoretical Perspectives and Meta-analysis. In: R. Capello and P. Nijkamp (eds.) Handbook of Regional Growth and Development Theories. Cheltenham, Edward Elgar, 256-281.

De La Potterie, B. V. P. (1997) Issues in Assessing the Effect of Interindustry R\&D Spillovers. Economic Systems Research, 9, 331-356.

Den Hertog, P. (2000) Knowledge-intensive Business Services as Co-producers of Innovation. International Journal of Innovation Management, 4, 491-528.

Drejer, I. (2002) Business Services as a Production Factor. Economic Systems Research, 14, 389-405.

Evangelista, R. (2000) Sectoral Patterns of Technological Change in Services. Economics of Innovation and New Technology, 9, 183-222.

Fagerberg, J. (2004) Innovation: A Guide to the Literature. In: J. Fagerberg, D. Mowery, and R. Nelson (eds.) The Oxford Handbook of Innovation. Oxford, Oxford University Press, 1-29.

Forni, M. and S. Paba. (2002) Spillovers and the Growth of Local Industries. The Journal of Industrial Economics, 50, 151-171.

Frenken, K., F. Van Oort and T. Verburg. (2007) Related Variety, Unrelated Variety and Regional Economic Growth. Regional Studies, 41, 685-697.

Gallouj, F. and M. Savona. (2009) Innovation in Services: a Review of the Debate and a Research Agenda. Journal of Evolutionary Economics, 19, 149-172.

Gehringer, A. (2012) A New Sectoral Taxonomy Based on Pecuniary Knowledge Externalities: Knowledge Interactions in a Vertically Integrated System. Economic Systems Research, 24, 35-55.

Geroski, P. (1992) Vertical Relations between Firms and Industrial Policy. The Economic Journal, $102,138-147$.

Giacomini, R. and C. W. Granger. (2004) Aggregation of Space-Time Processes. Journal of Econometrics, 118, 7-26.

Glaeser, E. L., H. D. Kallal, J. A. Scheinkman and A. Shleifer. (1992) Growth in Cities. Journal of Political Economy, 100, 1126-1152.

Guerrieri, P. and V. Meliciani. (2005) Technology and International Competitiveness: The Interdependence Between Manufacturing and Producer Services. Structural Change and Economic Dynamics, 16, 489-502.

Hauknes, J., and M. Knell. (2009). Embodied Knowledge and Sectoral Linkages: An Input-Output Approach to the Interaction of High- and Low-tech Industries. Research Policy, 38, 459-469.

Hoen, A. R. (2002) Identifying Linkages with a Cluster-Based Methodology. Economic Systems Research, 14, 131-146.

Jacobs, J. (1969) The Economy of Cities. New York: Random House.

Laursen, K. and I. Drejer. (1999). Do Intersectoral Linkages Matter for International Export Specialisation? Economics of Innovation and New Technology, 8, 311-330.

Laursen, K., and V. Meliciani. (2002) The Relative Importance of International Vis-a-Vis National Technological Spillovers for Market Share Dynamics. Industrial and Corporate Change, 11, 875-894.

Lesage, J. P. (2008). An Introduction to Spatial Econometrics. Revue d'économie industrielle, 123, $19-44$.

Los, B. and B. Verspagen. (2002). An Introduction to the Analysis of Systems of Innovation: Scientific and Technological Interdependencies. Economic Systems Research, 14, 315-322.

Love, I. and L. Zicchino. (2006) Financial Development and Dynamic Investment Behavior: Evidence from Panel VAR. The Quarterly Review of Economics and Finance, 46, 190-210.

Lundvall, B. A. (2009). Innovation as an Interactive Process: User-Producer Interaction to the National System of Innovation: Research Paper. African Journal of Science, Technology, Innovation and Development, 1, 10-34.

Metcalfe, J. S. (1994). Evolutionary Economics and Technology Policy. The Economic Journal, 104, 931-944.

Miller, R. E. and P. D. Blair. (2009). Input-Output Analysis: Foundations and Extensions. Cambridge: Cambridge University Press.

Miozzo, M. and L. Soete. (2001) Internationalization of Services: A Technological Perspective. Technological Forecasting and Social Change, 67, 159-185. 
Moretti, E. (2010) Local Multipliers. American Economic Review: Papers \& Proceedings, 100, $1-7$.

Muller, E. and A. Zenker. (2001) Business Services as Actors of Knowledge Transformation: The Role of KIBS in Regional and National Innovation Systems. Research Policy, 30, 1501-1516.

Neffke, F. and M. Henning. (2013) Skill Relatedness and Firm Diversification. Strategic Management Journal, 34, 297-316.

Nelson, R. R. and E. S. Phelps. (1966) Investment in Humans, Technological Diffusion, and Economic Growth. The American Economic Review, 56, 69-75.

Nickell, S. (1981) Biases in Dynamic Models with Fixed Effects. Econometrica, 49, 1417-1426.

Pavitt, K. (1984) Sectoral Patterns of Technical Change: Towards a Taxonomy and a Theory. Research Policy, 13, 343-373.

Pedroni, P. (2013) Structural Panel VARs. Econometrics, 1, 180-206.

Perez, C. (2010) Technological Revolutions and Techno-economic Paradigms. Cambridge Journal of Economics, 34, 185-202.

Peri, G. (2005) Determinants of Knowledge Flows and Their Effect on Innovation. Review of Economics and Statistics, 87, 308-322.

Porter, M. E. (1991) Towards a Dynamic Theory of Strategy. Strategic Management Journal, 12, 95-117.

Romer, P. M. (1986) Increasing Returns and Long-run Growth. Journal of Political Economy, 94, 1002-1037.

Souitaris, V. (2002) Technological Trajectories as Moderators of Firm-level Determinants of Innovation. Research Policy, 31, 877-898.

Stock, J. H. and M. W. Watson. (2001) Vector Autoregressions. Journal of Economic Perspectives, 15, 101-115.

Van Stel, A. J. and H. R. Nieuwenhuijsen. (2004) Knowledge Spillovers and Economic Growth: An Analysis Using Data of Dutch Regions in the Period 1987-1995. Regional Studies, 38, 393-407.

Verspagen, B. (1997) Measuring Intersectoral Technology Spillovers: Estimates from the European and US Patent Office Databases. Economic Systems Research, 9, 47-65. 